\title{
Psicoterapia de Vittorio Guidano E SUAS INFLUÊNCIAS EPISTEMOLÓGICAS
}

\author{
VITTORIO GUIDANO'S PSYCHOTHERAPY \\ AND ITS EPISTEMOLOGICAL INFLUENCES \\ PSICOTERAPIA DE VITTORIO GUIDANO Y \\ SUS INFLUENCIAS EPISTEMOLÓGICAS
}

Liliana Pena* Clara Costa Oliveira**

\section{Resumo}

Este artigo encontra-se estruturado basicamente em três partes. Na primeira, contextualizamos as concepçóes de Vittorio Guidano face às correntes psicoterapêuticas do século $\mathrm{XX}$, nomeadamente quanto ao comportamentalismo, ao cognitivismo e ao construtivismo. Fazemos notar que as várias tendências da psicoterapia dessa época se autorrotulavam a partir de conceitos advindos de outras áreas, sem terem o cuidado de indagar sobre os fundamentos epistemológicos nos quais elas se alicerçavam. Num segundo momento detemo-nos no embasamento epistemológico de sua teoria e metodologia psicoterapêuticas, focalizando-nos no papel que o cognitivismo cibernético teve no seu pensamento (nomeadamente, quanto à questão da observação), bem como na teoria biológica da autopoiesis, na qual nosso autor explicitamente se inspirou. Por fim, nos debruçamos com algum pormenor sobre o seu modelo sobre o conhecimento e experiência humana, que se traduz numa nova teoria da personalidade (organização pessoal, noção de si mesmo) e um novo sistema psicoterapêutico que enfatiza o papel do vínculo afetivo como modelador da identidade pessoal.

Palavras-chave: psicoterapia; Guidano; epistemologia; cognitivismo; autopoiesis.

* Universidade Óscar Ribas, Luanda, Angola.

** Universidade do Minho, Braga, Portugal. 


\section{Abstract}

This article is structured in three parts. At first, we contextualize the concepts of Vittorio Guidano in relation to psychotherapeutic currents of the twentieth century, particularly regarding behaviorism, cognitivism constructivism and others. We note that the various trends of psychotherapy labeled themselves according to concepts coming from other areas of study, without regard to their epistemological origins. Secondly we reflect on the epistemological foundation of Guidano's theory and psychotherapeutic methodology, focusing on the role that cyber cognitivism had in his thinking (namely, the question of observation, and self-observation), as well as the biological theory of autopoiesis, in which our author explicitly inspired himself. Finally, we center our attention on his model of knowledge and human experience that translates into a new theory of personality (regarding personal organization, as well as the notion of the self) and into a new system, that emphasizes the psychotherapeutic role of bonding in shaping personal identity.

Keywords: psychotherapy; Guidano; epistemology; cognitivism; autopoiesis.

\section{RESUMEN}

Este artículo se estructura básicamente en tres partes. Al principio, contextualizamos los conceptos de Vittorio Guidano con respecto a las corrientes psicoterapéuticas del siglo XX, sobre todo en relación con el comportalismo, el cognitivismo y el constructivismo. Tomamos nota de que las diversas tendencias de la psicoterapia en ese momento si se llamaban a sí mismos nombres provenientes de conceptos otras áreas, sin la precaución de preguntar acerca de las bases epistemológicas sobre la que se fundaban. En segundo lugar estamos reflejando el fundamento epistemológico de su teoría y metodología psicoterapéutica, centradas en el papel que el cognitivismo cibernético tenía en su mente (es decir, la cuestión de la observación), así como en la teoría biológica de la autopoiesis, en ella que nuestro autor se ha inspirado explícitamente Finalmente, nos detenemos en algunos detalles sobre su modelo en el conocimiento y la experiencia humana, que se traduce en una nueva teoría de la personalidad (organización personal, la noción del yo) y un nuevo sistema que destaca en psicoterapia el papel de la vinculación en la unión y en la formación de la identidad personal.

Palabras-clave: psicoterapia; Guidano; epistemología; cognitivismo; autopoiesis. 


\section{Introduçáo}

Este artigo encontra-se estruturado basicamente em três partes. Na primeira, contextualizamos as concepçóes de Vittorio Guidano face às correntes psicoterapêuticas do século XX. Num segundo momento detemo-nos no embasamento epistemológico de sua teoria e metodologia psicoterapêuticas. No final, nos debruçamos com algum pormenor sobre o seu modelo sobre o conhecimento e experiência humana, que se traduz numa nova teoria da personalidade e num novo sistema psicoterapêutico enfatizando o papel do vínculo afetivo como modelador da identidade pessoal.

A questão central deste artigo teórico se pode colocar deste modo: a psicoterapia de V. Guidano deve mais ao conhecimento produzido nas correntes psicoterapêuticas ou àquele construído em outras áreas do saber, transposto para a sua concepção e prática psicoterapêuticas? Para tal averiguarmos, recorremos à metodologia qualitativa, de tipo hermenêutico, por análise documental dos escritos do autor e dos seus mais reconhecidos discípulos e comentadores.

\section{Abordagem breve da história da psicologia clínica}

A autonomização da psicologia terapêutica e o seu reconhecimento são tardios na história da humanidade. Na tradição filosófica - pelo menos até final do séc. XIX - aquilo a que hoje chamamos psicologia seria o estudo da alma, em sentido kantiano. $\mathrm{O}$ reconhecimento científico exigiu uma demarcação da psicanálise freudiana (logo, da medicina), tendo tal sido conseguido pela colagem ao paradigma científico da época (o mecanicismo newtoniano), cujas bases epistemológicas principais são, por um lado, a dualidade sujeito/objeto (da qual seguem sociedade/natureza, alma/corpo, mente/cérebro, etc.); por outro lado, a crença (não assumida enquanto tal) da explicação dos fenômenos observados como representaçóes fieis da realidade; a terceira principal caraterística pode ser descrita como o recurso em exclusivo às causalidades de tipo eficiente e material (usando a linguagem aristotélica) para explicação dos fenômenos, bem como para sua eventual replicação/correção. Dessa linhagem nasceu a psicoterapia comportamentalista, latu sensu, que reinou como paradigma.

A psicoterapia também deve bastante a filósofos como Wundt e James, este último especialmente interessado em formas de compreensão do funcionamento da psiche humana bastante diferenciada da linhagem acima referenciada, como a parapsicologia, e em que o papel da causalidade final, ou teleológica, continua 
a resistir, concretizando-se em questóes como as ligadas à intencionalidade de quem pratica a ação, bem como daquele que a recebe/reage.

A história da epistemologia da psicologia é pouco consensualizada, e isso é compreensível dada a sua juventude no domínio dos saberes produzidos pela nossa espécie (compare-se com a filosofia ou com a arte, por exemplo). Usualmente, porém, considera-se a linhagem de Brentano como aquela que acabaria por proporcionar uma revolução científica (Kuhn, 1962) na psicologia, desfocando-a lentamente do comportamento para o mundo intrapsíquico, da consciência, da mente em linguagem moderna (lembremos que Brentano foi mestre do pai da fenomenologia filosófica Edmund Husserl).

Assim, na recuperação dessa linhagem minoritária, ocorre a revolução cognitivista, ou a $1^{\text {a }}$ revolução cognitivista, como alguns consideram. Dentro do cognitivismo verificaram-se várias facções, tal como no comportamentalismo surgiram nova figuras de proa, como Skinner.

Para muitos, o cognitivismo, na psicologia, começou com Miller, em 1956 no MIT, com a sua comunicação The magical number seven, plus or minus two: some limits on our capacity for processing information. A influência do cognitivismo cibernético e da filosofia analítica (sobretudo daquela ligada ao estudo do cérebro) foi explicitada em vários dos psicólogos conotados com o cognitivismo na psicologia (como Mahonhey, Cautela, D’Zorilla, Beck, entre vários outros). Essa mescla de influências de conceptualizaçóes diferentes (e, por vezes diferenciadas dentro das suas áreas de origem: pense-se na diferença entre Searle e Dennett, por exemplo), colocou essa corrente da psicologia numa situação de fragilidade teórica da qual poucos conseguiram sair. Alguns passaram a intitular-se "construtivistas", proporcionando ainda uma maior confusão em termos epistemológicos (Morales, 2008).

Com efeito, o construtivismo em epistemologia surgira com o biólogo (autointitulado epistemólogo) Piaget, que tentara criar um compromisso entre o idealismo e o realismo filosófico, perseguindo explicitamente o sonho kantiano, mas sem recurso a entidades transcendentais, para compreender a aprendizagem e a produção de conhecimento, sempre alicerçado na dimensão biocorporal, obviamente, da qual a psicologia seria uma seção. Do ponto de vista filosófico, o construtivismo epistemológico caracteriza-se por explicar aqueles fenômenos por processos sequenciais, por etapas triádicas, movimento no qual se vão formando estruturas (que corresponderiam às categorias do entendimento kantiano).

Os psicólogos cognitivo-construtivistas (que alguns consideram emergir de uma $2^{\mathrm{a}}$ ou $3^{\mathrm{a}}$, conforme os autores, revoluçóes dentro do cognitivismo) fixaram-se, no entanto, usualmente na dimensão da construção do conhecimento 
por parte do sujeito, dirigindo-se para aquilo que na epistemologia filosófica é apelidado há centenas de anos como "idealismo"; veja-se o caso de Ernst von Glaserferd, no que respeita ao "construtivismo radical". "In its most extreme expressions, radical constructivism comes close to the classic position of ontological idealism [...]" (Mahoney, 1991, p. 111).

$\mathrm{Na}$ história da psicoterapia no século XX surgiram várias novas teorias e métodos, tentando deter o poder do comportamentalismo. O mundo cultural, para além da psicologia, ajudava a incrementar essa falta de clareza e de discernimento, pois em várias áreas científicas autores se reclamavam como pós-estruturalistas, pós-modernos, etc. Dessa linhagem surgiram ainda a psicologia narrativa e o construcionismo social (Gergen \& Kaye, 1992; Gonçalves, 1994; 2002).

Alguns psicoterapeutas, porém, não se perderam nessa confusão, antes tendo tido a preocupação de alicerçar as suas crenças e metodologia terapêuticas em bases epistemológicas firmes, recorrendo à biologia e à cibernética, de onde tinham surgido os conceitos construtivismo e cognitivismo. Um deles foi Vittorio Guidano, que tivemos o prazer de conhecer pessoalmente, para além de algumas outras personagens que fizeram parte desses momentos táo criativos e táo conturbados da psicoterapia contemporânea.

Daí defendermos que para compreendermos a sua tipologia psicoterapêutica se torna necessário conhecer, ainda que brevemente, as teorias das quais emergiu o seu pensamento (autodenominado "pós-racionalista"), nomeadamente sobre a cognição humana, que sempre possuiu um papel importante na linhagem histórica da psicologia à qual ele pertence.

Para Vittorio Guidano (1990) a cognição não é meramente noética (raciocinativo-dedutiva) mas também motora (teoria motora da mente), sensorial, perceptiva e, logo, emocional; devemos lembrar que emoção significa etimologicamente colocar em ação (emovere) (Balbi, 2004, p. 279). Assim, a organização da própria experiência não pode nunca se resumir a ser uma processadora passiva de informação exterior: “[...] o 'significado pessoal' está intimamente ligado à experiência humana e ao conhecimento que se lhe atribui, em primeiro lugar, de forma emocional e, depois, explicativa ou conceptual" (Pena \& Oliveira, 2012, p. 671).

\section{Cibernética e cognição}

O conhecimento sobre a cognição humana deve muito à cibernética (Varela, 2001, p. 287), cuja história pode ser dividida em três momentos. No primeiro, começou por estudar a ordenação dos processos das máquinas construídas pelos 
seres humanos; o segundo corresponde ao seu apogeu nos anos 20 até ao "pós-guerra”, com a constituição do Biological Computer Laboratory (BCL) de von Foerster, entre outros. Referimos aqui, dado o contexto no qual se inscreve este texto, o papel de von Foerster na construção de um modelo simples que lhe permitiu criar o seu princípio de order from noise, que ele acreditava diferenciar os seres vivos dos restantes entes (de notar que Atlan construiu a sua teoria de complexidade pelo ruído a partir desse princípio de von Foerster). Von Foerster (em continuidade com os estudos de Shannon sobre informação) tomou como desafio deixar atuar sem qualquer controle aspectos ruidosos dentro de um sistema considerado organizado. As suas experiências basearam-se em modelos simples, de cubos magnetizados, tendo possibilitado compreender que a informação tinha a ver com a diferenciação; Shannon já demonstrara que sistemas informacionais com repetição contínua da mesma informação não acrescem informação, mas antes a anulam (como, por exemplo, na mensagem pretensamente veiculada por um telégrafo).

Para von Foerster, a informação decorre do âmbito observacional ${ }^{1}$ e não da mensagem em si. Esse postulado distingue-se do idealismo filosófico por este fundamentar o significado atribuído ao mundo a partir de verdades interiores, usualmente transcendentais, ao passo que na perspectiva de von Foerster o significado depende do contexto naturalizado (as crenças do observador, em linguagem filosófica pragmatista).

A segunda contribuição muito importante - do ponto de vista epistemológico - da investigação de von Foerster foi que a aleatoriedade, o ruído, no entender de um observador, podem ser fonte de significado na vida de um outro, ou seja, os seres humanos não constroem significação (aprendem) apenas pela ordenação informacional, mas sobretudo pelo ruído.

É a von Foerster que se remete o mérito de ter sido o primeiro a precisar e formalizar essas ideias, sob o nome do princípio "ordem pelo ruído". [...]. Henri Atlan retomou-as e desenvolveu-as, propondo um formalismo capaz de ultrapassar as duas limitaçóes clássicas da teoria da informação de Shannon: a saber, que ela não pode explicar nem a criação de informação, nem a significação da informação (Dupuy, 1982, p. 102).

Para von Foerster, o seu modelo exemplificava metaforicamente algo em que ele acreditava e que o tinha motivado a ser um dos fundadores do BCL: que os seres vivos conseguiam organizar-se mesmo em situaçóes de ruído, desde que estivessem eles saudáveis. A magnetização dos cubos correspondia à capacidade auto-organizativa desse tipo de ser. Apesar de toda a investigação investida, o BCL 
nunca conseguiu criar em laboratório uma máquina que tivesse complexidade suficiente para se auto-organizar como uma simples célula.

Ashby é o principal representante da segunda corrente cibernética, focalizada nas questóes da Inteligência Artificial; ficou conhecida como cognitivismo cibernético. O objetivo era comparar e diferenciar os seres vivos com seres maquínicos, de construção humana, bem como estudar os fenômenos da observação, no seguimento da $1^{\text {a }}$ cibernética.

O mundo real fornece o subconjunto que é, o produto-espaço representa a incerteza do observador; o produto-espaço pode, pois, mudar se o observador muda; e dois observadores podem legitimamente usar diferentes produtos-espaço dentro dos quais gravar o mesmo subconjunto dos próprios eventos em alguma coisa específica. O "constrangimento" é então uma relação entre observador e coisa: as propriedades de qualquer constrangimento particular dependem de ambas: da coisa real e do observador. Segue-se que uma parte substancial da teoria da organizaçáo dirá respeito às propriedades que não são intrínsecas à coisa, mas são relacionais entre observador e coisa (Ashby, 1962, p. 258).

A terceira fase da cibernética (neo-conexionista) irrompe nos anos 80 , estudando o funcionamento neuronal tendo por base as redes cibernéticas, simulando o dinamismo processual das redes neuronais. Considerava o funcionamento neuronal por causalidade múltipla, tendo descoberto que a complexificação das redes neuronais se encontra muito mais conectada à interaçáo processual do que ao papel desempenhado por alguns componentes.

A estratégia é construir um sistema cognitivo começando não com símbolos e regras, mas começando com componentes simples que se conectariam dinamicamente de maneira densa. Nesta perspectiva, cada componente opera apenas no seu meio local, de modo que náo existe algum agente externo que se torne o eixo do sistema, como anteriormente. Mas, devido à constituição da rede do sistema, há uma cooperação global que espontaneamente emerge quando os estados de todos os "neurônios" participantes atingem um estado de satisfaçáo mútua. Em tal sistema, então, não há necessidade de uma unidade de processo global para guiar a operação completa. Esta passagem de regras locais para coerência global está no coração daquilo que usualmente é apelidado de auto-organização durante os anos cibernéticos (Varela, Thompson, \& Rosch, 1991, p. 88). 
Dessa corrente surgiu o emergentismo, que além de investigar o funcionamento simulado das redes neuronais descreve também os diferentes estádios emergentes dessas interações processuais, que ocorrem por acaso (Varela et al., 1991; Varela, Rosch \& Thompson, 2001). Por fim, surgiu a "enação" como a nova orientação interpretativa da cognição, como atuação ou ação interativa (e interconstitutiva a simultâneo) de mentes em mundos/realidades. O conhecimento é ação no mundo e não sua representação. Sob esse ponto de vista, o mundo é algo que emerge a partir de como nos movemos e agimos em relação dinâmica com o meio. Conhecer é viver e viver é aprender (Ojeda, 2001; Varela, 2001; Maturana \& Varela, 1972).

Em resumo, a corrente enatista consiste em dois pontos: (1) percepção consiste em ação guiada pela percepção; (2) estruturas cognitivas emergem de padróes sensoriomotores recorrentes que permitem à ação ser guiada pela percepção. [...] Assim, a preocupação global numa perspectiva enatista não é determinar como algum mundo percepcionalmente independente será recuperado; é, antes, determinar os princípios comuns ou ligações validadas entre os sistemas motor e sensorial, que explicam como a ação pode ser perceptualmente guiada num mundo percepcional-dependente (Varela et al., 1991, p. 173).

\section{Cognição e (r)evoluçóes da psicologia}

No ponto de vista de H. Gardner, se os cientistas cognitivos querem conhecer os aspectos essenciais da cognição, terão de deslindar e construir as pontes de ligação entre as suas disciplinas e áreas de estudos vizinhas, pelo que será necessário conhecer as diversas histórias, métodos e problemas particulares que caracterizam outras ciências. Nessa perspectiva, e parafraseando Howard Gardner (2002, p. 514), podemos dizer que a filosofia oferece as principais questóes e ajuda a avaliar se elas estão a ser abordadas com sucesso.

Enquanto no mundo cultural (pela mão do filósofo François Lyotard) se anunciava a transição da modernidade para a pós-modernidade, na psicologia ocorreu uma alteração equivalente, que se traduziu numa evolução do conceito de mente: do racionalismo (que encara a mente como passiva e processadora de informação tipo computador/máquina -estudos da mente tendo como base o cérebro, na linhagem da filosofia da mente, de autores vários, tratados com humor e rigor por Lodge, 2002; cf. também Balbi, 2004) para o pós-racionalismo, que faz emergir um novo conceito de mente ativa e capaz de organizar, ordenar as 
experiências, das quais extrai significado. Esses significados esboçam/constituem a identidade do sujeito, que surge sob a forma de narrativas pessoais em contexto psicoterapêutico, sendo, pois, o método de auto-observação essencial na avaliação e intervenção em psicoterapia pós-racionalista (Castrillón, 2011).

Os construtivistas, em psicologia, preocupam-se com a forma como as pessoas constroem os significados que extraem da realidade, enquanto os pós-racionalistas se centram no modo como cada pessoa constrói o seu próprio significado. O pós-racionalismo mantém importantes semelhanças epistemológicas com o construtivismo, como por exemplo: o sentido de que temporalidade, narratividade e identidade constituem a unidade existencial da experiência humana; a noçấo de mente (como um sistema proativo, auto-organizado e construtor de significados) e a condição intersubjetiva e autorreferencial do conhecimento humano (Balbi, 2004, p. 21 e 270). Nas palavras de Guidano (1991, p. 52), "a manutenção de um sentido de individualidade pessoal e unicidade ao longo da vida resulta da atividade autopoiética [teoria da autopoiesis, de Maturana] do sujeito".

Há muitos sistemas autônomos que não são sistemas vivos. Seria um erro considerar autonomia como a característica fundamental da autopoiesis. O ponto central é que nós temos uma rede fechada produzindo moléculas que, por seu lado, produzem a rede que as produz. [...] Autopoiesis é o modo e o caminho específicos de os sistemas vivos serem autônomos, concretizando a sua autonomia (Maturana \& Poersken, 2004, p. 101).

A perspectiva pós-racionalista enfatiza o papel das emoções na construção de significados. É essa noção de conhecimento que leva Guidano a definir o seu modelo de pós-racionalista, na medida em que vai além do racionalismo, mas não num sentido antirracionalista. As emoções são entendidas como constitutivas da nossa estrutura e sempre presentes em cada atividade humana (Ruiz, 2002, Damásio, 2001; Balbi, 1994; 2004).

Conseguimos detectar emoçôes de fundo através de pormenores subtis relacionados com a postura corporal, com a velocidade e contorno dos movimentos, com a modificação mínima na quantidade e na velocidade dos movimentos oculares e no grau de contração dos músculos faciais (Damásio, 2001, p. 73).

Guidano (1990) apresenta, assim, um ponto de inflexáo da Psicologia e propóe o conhecimento humano desde uma perspectiva ôntica (ou ontogenética, 
preferencialmente), isto é, o conhecimento não é mais uma cópia da realidade externa, mas uma expressão da capacidade que cada organismo tem de se auto-organizar e de ordenar a sua experiência. A influência da teoria biológica da autopoiesis é assumida por Guidano; nela o desenvolvimento de uma criatura de uma espécie ocorre a partir de desafios constantes de superação de obstáculos; a superação de cada um deles coloca as crias em níveis de aprendizagem superiores. Tal é conseguido pela sua capacidade autopoiética, que opera selecionando as perturbaçóes do meio que permitam aos organismos complexificarem-se na interdependência acoplativa com os seus nichos, constituindo unidades compostas.

Os sistemas autopoiéticos podem interatuar entre si, sem perder a sua identidade, enquanto as suas respectivas modalidades de autopoiesis constituem fontes de perturbações mútuas compensáveis. Mais ainda, devido a sua organização homeostática, os sistemas autopoiéticos podem acoplar-se de maneira a que as suas respectivas autopoiesis se especifiquem durante o acoplamento, dentro das margens de tolerância e variação determinadas pelo acoplamento. [...] Tal sistema composto será necessariamente definido como unidade pelas relaçóes de acoplamento dos sistemas autopoiéticos que o integram, num espaço especificado pela natureza do acoplamento, e continuará a ser uma unidade enquanto os componentes conservarem a autopoiesis que thes permite entrar nessas relaçóes de acoplamento. (Maturana \& Varela, 1972, p. 67-68).

Esse processo organizativo homeostático é feito pela organização fechada (e não isolada) dos seres vivos, enquanto a sua estrutura permite interação com o nicho e no nicho. Dado que a organização se subordina à estrutura, qualquer ser vivo saudável possui essa capacidade autopoiética de aprender em qualquer momento da sua vida. $\mathrm{O}$ fato de Maturana ter escolhido uma palavra que remete para criatividade (poiesis) não é ocasional, dado que não se trata apenas de uma homeostasia de retorno ao estado anterior ao da perturbação, mas também à possibilidade de criaçáo de novos processos e componentes orgânicos face a essas perturbaçôes. Permitir o ruído e evitar o totalmente caótico para o organismo é algo que constitui um saber orgânico extraordinário.

Em Guidano é o sujeito autoconsciente que se auto-observa (na sua multidimensionalidade) que introduz ordem na realidade observada, atribuindo-lhe um reflexo da sua própria estrutura - esse processo de auto-observação é, portanto, autorreferencial (Balbi, 1994), em continuidade com o $2^{\circ}$ princípio da teoria autopoiética ("tudo o que é dito é dito por um observador"): 
Não há patologias no domínio biológico. O gato não é um tigre subdesenvolvido; um tigre não é um gato patologicamente arrogante. [...] Isto significa que todas as formas de vida têm que ser aceitas. [...] Patologia não é uma característica de um mundo existindo independentemente de um observador: uma doença aparece como uma condição que observadores - de acordo com as suas inclinaçóes - podem considerar indesejável (Maturana \& Poersken, 2004, p. 123).

Ruiz (2002) adianta que não há consciência de nós próprios sem autoengano (Quińones, 2001, p. 31), sendo o autoengano que nos permite manter a coerência narrativa, privilegiando um modo de significaçáo no qual nos autorreconhecemos ao longo do tempo (Salgado, 2004, p. 368).

\section{Modelo psicoterapêutico de Guidano}

A perspectiva psicoterapêutica do modelo de terapia cognitiva tradicional baseava o seu foco de intervenção no aumento do autocontrole das emoçóes perturbadoras, para se restabelecer o equilíbrio perdido. Esses terapeutas viam a mente como um computador (processador de informação, passivo) e davam relevância à racionalidade sobre as emoçôes no processo de mudança terapêutico. Acreditavam que mudando a forma de pensar se mudaria também a forma de sentir (Balbi, 1996; Quiñones, 2001), sendo o seu objetivo principal a modificação de crenças irracionais por outras crenças mais racionais e adaptativas, usando o método da persuasão. Esse tipo de psicoterapia tinha por base a "metáfora" do processamento de informação. Encontram-se exemplos nas formas terapêuticas de A. Beck, A. Ellis e D. Meichenbaum, entre outros (Gabalda, 1999, p. 39).

Guidano, como Maturana, afirma que os organismos são sistemas fechados à informação. A compreensão das hipóteses de Maturana é de crucial importância para alcançar um entendimento cabaz da perspectiva pós-racionalista, que surgiu em oposição à corrente computacionalista na psicologia cognitiva (Balbi, 2004, p. 224).

O modelo de terapia pós-racionalista surge com a obra The self in process (1991), de Vittorio Guidano. No entanto, essa forma terapêutica já tinha sido esboçada em outras obras como: The complexity of self: a developmental approach 
to psychopathology and therapy (1987) e Cognitive processes and emotional disorders (1983), esta última com a colaboração de Gianni Liotti.

Vittorio Guidano propóe um novo modelo sobre o conhecimento e experiência humana que se traduz numa nova teoria da personalidade (organizaçáo pessoal, noção de si-mesmo) e um novo sistema psicoterapêutico que enfatiza o papel do vínculo afetivo como modelador da identidade pessoal (Balbi, 2004). O objetivo dessa terapia é conduzir estrategicamente o cliente a uma reconstrução da sua experiência imediata (auto-organizar-se) através do mecanismo de auto-observação. O cliente é conduzido a aumentar a autoconsciência e compreensão sobre a própria maneira de organizar a experiência e o seu significado pessoal, aumentando o seu nível de autorreferencialidade (reduzindo portanto o nível de autoengano) e assim permitir que integre experiências (que antes eram) discrepantes que estiveram na origem da sua crise ou descontinuidade na narrativa pessoal

$\mathrm{Na}$ terapia narrativa, objetiva-se separar linguisticamente a pessoa do seu problema; para isso, o terapeuta busca produzir a "externalizaçáo do problema”. Nessa prática, compreende-se que não são as pessoas nem suas relaçôes que constituem o problema, mas sim o sentido que as pessoas dáo para algumas situaçôes de suas vidas (Carrijo \& Rasera, 2010, p. 128).

Se a experiência imediata desafia os padrões habituais de significação, essa mudança na vivência subjetiva dispara/provoca oscilação afetivo-emocional que dá origem à reorganização pessoal. É aqui que a qualidade da autoconsciência que a pessoa tem de si mesma vai promover a sua organização (manutenção de coerência) e esta pode dar-se em dois sentidos: regressivo ou progressivo; no primeiro caso são mantidos os padróes de coerência e aumenta o nível de autoengano, excluindo-se determinadas experiências do campo de significação interna; no segundo, a pessoa altera os seus padrões habituais de significação no sentido de acomodar novas experiências, que passam a ser significativas (Balbi, 1994; Salgado, 2004).

A construção de um sentido de identidade pessoal e único parece ser a característica distintiva do modo como um sistema individual constrói a sua ordem autoreferencial, de modo que a progressiva diferenciação de um sentido de um self parece estar desde o início conectada com o equivalente desenvolvimento cognitivo/emocional (Guidano, 1987, p. 55). 


\section{Identidade e vinculo afetivo}

Ao longo da nossa história de desenvolvimento (narrativa), vamos adquirindo tonalidades emocionais que a partir dos dois anos de idade (e com o surgir da individualização) se constituem sob a forma de padróes de apego ou self defining categories (Guidano, 1996). Essas tonalidades emocionais vão contribuir para que a criança estabeleça o seu sentido de si mesma, da sua individualidade e o sentido específico de relacionamento com os outros. Nas palavras de Ruiz (2002) o vínculo (afetivo) está intimamente ligado à experiência intersubjetiva. Uma criança, ao vincular-se aos seus pais, desenvolve um sentido de si mesma que depende do tipo de vinculação estabelecido e constrói a sua organização de significado pessoal (OSP). Assim, por exemplo, num padrão vincular (A) que se estabelece pela inacessibilidade afetiva dos pais serão ativadas emoçóes de desespero, solidão e raiva dirigida aos mesmos. A criança começa a ter um sentido estável de si mesma pela recorrência dessas emoçóes na sua experiência imediata e desenvolve um tipo de apego ou padrão vincular evitante (A). O desenvolvimento dessas tonalidades emocionais guia o aparecimento de outras, que vão começando a estruturar na criança o sentido de si mesma e o surgimento de outras emoçóes como, por exemplo, o medo. Poderá haver outras dimensões de significado, mas nunca mais de 9 ou 10, visto que o significado pessoal reflete o padrão de organização emocional e psicofisiológica, e poucas emoçōes fundamentais ou básicas existem (Guidano, 1994b).

Guidano (1994b) refere que um padrão vincular (e sua estabilidade) é resultado de um processo de seleção e estabilização do fluxo de estados internos recorrentes e da autopercepção que a criança elabora a partir da avaliação e reconhecimento que experimenta na relação. As crianças têm duas possibilidades de avaliar as suas relaçôes com os pais: quando mãe e pai são acessiveis a qualquer momento a criança desenvolve um padrão vincular seguro (B); se os pais não são acessiveis para a criança, e ela sabe que pode obter rejeição às suas demandas, então evita os contatos, ou seja, desenvolve o padrão vincular evitante (A); a outra possibilidade de apego denomina-se de ambivalente/ansioso ou coercivo (C), uma vez que a acessibilidade dos pais não é previsível, ora são acessíveis, ora não, e por isso a criança começa a ser coerciva para obter a constante atenção dos pais e assim se beneficiar da acessibilidade deles, tornando esse acesso previsível. O estudo desses processos de apego/vinculaçáo foi central para a evolução do cognitivismo pós-racionalista, uma vez que no ser humano, desde o nascimento e durante todo o seu ciclo de vida, os padróes vinculares evidenciam ser aspetos fulcrais para a definição e/ou estabelecimento do sentido de si mesmo (Quiñones, 2001; Balbi, 2007). 
O conhecimento é assim, primariamente afetivo e secundariamente reorganizado pela e na linguagem (Zagmutt, 2006), porque é a linguagem que permite destacar o conteúdo informativo da experiência imediata (de tonalidade afetiva), reconstruindo-a e explicando-a.

A partir da Segunda Cibernética, principalmente, mas também com a decisiva contribuição do linguistic turn, ainda nas primeiras décadas do século XX, começa uma virada paradigmática, que vai colocar o papel auto-constitutivo e de autoria de cada ser humano como ser que se constitui na linguagem. Emerge uma nova compreensão do que significa ser humano. Neste sentido, começa-se a valorizar o papel das narrativas singulares como instrumento de autoconstruçáo, o que, mais tarde, com o surgimento de uma biologia complexa, surgida no berço cibernético, vai ser endossado com a emergência do conceito de Autopoiesis dos biólogos chilenos $\mathrm{H}$. Maturana e F. Varela (Boettcher \& Pellanda, 2012, p. 13).

A linguagem assume uma dupla dimensão da experiência, o que se torna importantíssimo em contexto terapêutico, uma vez que pertence à habilidade do terapeuta compreender e distinguir entre os dois níveis; o seu trabalho situa-se sempre nessa interface entre experiência imediata (do self protagonista) e da sua explicação/narrativa (do self narrador - observador de si próprio) pois a reordenação da experiência de vida não é mais que a visão pessoal do mundo externo (Guidano, 1990; 1996; Abreu \& Roso, 2003; Balbi, 2007), portanto é um processo aberto que se desenvolve por toda a vida na busca constante de uma verdade narrativa que permita reorganizar a própria história, produzindo um sentido de continuidade e coerência entre o self protagonista e o self narrador (Guidano, 1996).

A contribuição da virada linguística foi, sem dúvida, ter ajudado a mudança de falarmos da experiência como um meio de representaçáo para falarmos da linguagem como meio-instrumento que, como se verificou, tornou mais fácil colocar de lado a própria noçáo de representaçáo. [...] Desde que a filosofia foi libertada daquilo que Quine e Davidson chamaram "os dogmas do empirismo" com os quais Russell, Carnap e Ayer (embora Frege náo) se implicaram, proposiçôes deixaram de ser pensadas nem como expressōes de experiência, nem como representaçôes de realidades extraexperienciais. Antes, elas foram pensadas como sequências de marcas e ruídos usadas pelos seres humanos no desenvolvimento e procura de práticas sociais (Rorty, 1992, p. 373). 


\section{Metodologia e técnica da terapia cognitiva pós-racionalista}

Vittorio Guidano refere que o setting terapêutico é um trabalho entre dois peritos: o terapeuta, que é perito em princípios psicológicos (porque tem experiência nisso) e o cliente, que é (o único) perito em si mesmo (Guidano, 1990, p. 83). Em consulta, o problema que o cliente traz constitui a forma pessoal de ordenar a sua realidade, sendo o seu problema correspondente à forma como foi afetado/perturbado por determinada realidade, independentemente do acontecimento em si. Interessa-nos pois, enquanto terapeutas, esse modo como o cliente organizou a experiência (imediata) desse momento. Cada pessoa tem experiências, sensaçóes, emoçôes distintas face ao mesmo acontecimento, quer isso dizer que são afetadas ou perturbadas de diferentes formas, e mais que experiência, é sobretudo (inter)subjetiva, individual e emocional, o que demonstra uma propriedade do conhecimento (de todos os seres vivos): a autorreferencialidade. Interessa pois a realidade da própria pessoa, que tende a ser interiorizada de forma coerente com a sua organização de significado pessoal (em coerência interna) de forma a manter uma continuidade estável daquilo que somos e nos identifica (Guidano, 1990; Abreu \& Roso, 2003).

O significado pessoal corresponde a uma organização unitária do domínio emocional e essa organização unitária pode dar origem a diversas estruturas narrativas pessoais. Segundo Guidano existem quatro organizaçóes de significado pessoal - OSP: dap, depressiva, fóbica e obsessiva - que constituem um sentido particular do "si-mesmo", do Self.

Uma organização pessoal tipo dap (eg: desordem alimentar) possui uma percepção pessoal desfocada, por isso, e apesar da necessidade de se sentirem aceitos, esses clientes têm também a necessidade de se oporem ao outro (com quem é estabelecida a relação) para se sentirem autônomos e independentes. Esse tipo de organização pessoal tende a entrar em jogos relacionais, ou de poder.

$\mathrm{Na}$ organização depressiva, o repertório emocional envolve temas de luto e perdas reais ou afetivas; na organização fóbica encontram-se temas sobre a sensação de ameaça, constrição, perigo e necessidade de proteção; por último, na organização do tipo obsessivo encontram-se descrições sobre perfeccionismo, dificuldade em tomar decisões, ritualização/compulsão (rituais de ordem, pôr tudo em ordem), moralismo, oscilação emocional de "tudo ou nada" (Guidano, 1994b; 1994a; Quiñones, 2001).

Em Terapia Cognitiva Pós-racionalista, o problema trazido à consulta deve ser reformulado, inscrito na história/narrativa de vida do cliente, uma vez que a sua tendência é apresentar o problema como estranho e externo a si próprio. Toda 
a reformulação tem a intenção de transformar o problema em interno, como constituinte da forma de ser do cliente (Guidano, 1990; 1991, Balbi, 1997). Essa constitui a primeira etapa do processo terapêutico: preparação do contexto clínico e interpessoal.

Após a reformulação do problema, começa-se a reconstruir a dinâmica entre experiência imediata e explicação que o cliente tem sobre problema reformulado (Balbi, 1996) até que seja capaz de reconhecer o seu modo de organizar a experiência; faz-se reconstrução da dimensão da vida atual (do presente) para encontrar o momento em que teve início a perturbaçáo ou desequilíbrio e depois começa-se a reconstruir o estilo afetivo (duas fases da segunda etapa) e vê-se como organiza e ordena a vida afetiva (Guidano, 1992). As fases de cada relação significativa são vistas em moviola como um filme, observado de ambos os pontos de vista: objetivo (de fora) e subjetivo (de dentro), treinando o cliente a ser flexível na análise do seu estilo afetivo e a descobrir o seu significado pessoal, a sua coerência interna/lógica.

A terceira etapa, reconstruçâo da história evolutiva, é a que produz mais turbulências afetivas/emocionais e algum sofrimento, porque se vão reformular e reorganizar as estruturas básicas dos padróes de coerência interna do cliente, uma vez que o problema visto inicialmente como exterior a si próprio passa a ser autorreferido - o cliente reconhece-se e não gosta. Torna-se por isso imperativo que o terapeuta conheça as diferentes organizações de significado pessoal (OSP), já que a afetividade é muitas vezes motivadora de transtornos clínicos (Quiñones, 2001, p. 122).

Podemos assim dizer, que a autoestima (assim como o autoconceito) se relaciona com o processo de autoengano, já que o ser humano como primata intersubjetivo tem necessidade de perceber a imagem de si mesmo como aceita, reconhecida e legitimada pelos outros (Guidano, 1994b; 1994a; Balbi, 1994). Nenhum ser humano pode tolerar uma imagem consciente de si com um baixo nível de aceitabilidade social, pois isso levaria à desintegração e desorganização do próprio sistema (Ruiz, 2002).

Além da manutenção da congruência interna e continuidade de si mesmo, o processo de autoengano permite regular a ativação emocional do sujeito prevenindo oscilações emocionais muito acentuadas (entre emoçóes positivas e negativas). Esse aspecto é muito importante para a forma como o sujeito constrói e organiza a sua experiência e história individual (organização de significado); pois, para manter a estabilidade emocional e evitar oscilaçóes, o sujeito tem de selecionar os eventos que considera significativos e os que não o são. Os eventos que produzem ativação emocional serão excluídos da consciência, considerados discrepantes. Esse 
processo dá-se de acordo com cada organização de significado pessoal. Por exemplo, os depressivos são pessoas mais sensíveis à percepção de perda (no entanto, percebem toda a realidade em termos de perda) mas não se dão conta dessa percepçáo da realidade, mantendo assim baixa ativação emocional. No caso do fóbico a sua maior sensibilidade é à constrição, no entanto nunca reconhecem a situação de constrição, apenas a manifestam fisicamente, por exemplo sentindo falta de ar ou um aperto no peito (Guidano, 1987, p. 148; 1996; Balbi, 2007). Pelo que

o autoengano emerge como uma atividade de construção/manutenção do sentido de identidade, isto é, o que se designa como falso é a verdade mais provável para a pessoa em causa, isso significa que tal interpretação que julgamos errónea mantém a continuidade narrativa da pessoa (Salgado, 2004, p. 245).

Salgado (2004) defende concordantemente com Guidano (1991) que o autoengano pode ser considerado um produto identitário, ou da auto-organização identitária na medida em que se relaciona com o auto-(re)conhecimento e desempenha um papel de destaque na manutenção da coerência interna.

Segundo a concepção do pós-racionalismo de Guidano (1992), ser pessoa implica ter a habilidade e/ou flexibilidade de se ir regulando ontogenicamente, face às circunstâncias que a vida apresenta. A maior parte das pessoas faz isso de acordo com a sua organização de significado pessoal ou dimensão de coerência sistêmica sem desenvolverem sintomas. Nessa perspectiva, normalidade, neurose ou psicose não são considerados estados fixos, nem enfermidades ou conteúdos da consciência, são modos de processamento, dimensôes de coerência sistêmica, formas de combinação e recombinaçáo do significado pessoal que qualquer uma das organizaçōes pode assumir. Cada organização (OSP) corresponde a uma forma de ordenar o conhecimento a um caminho evolutivo específico que se pode compreender e descrever em termos da sua relação com os padrôes vinculares, como vimos.

\section{Conclusão}

Retomando a questão inicial por nós colocada - a psicoterapia de V. Guidano deve mais ao conhecimento produzido nas correntes psicoterapêuticas ou naquele construído em outras áreas do saber, transposto para a sua concepção e prática psicoterapêuticas? -, iremos agora respondê-la de modo explícito. 
As concepções práticas psicoterapêuticas de V. Guidano foram fortemente influenciadas pelos saberes vindos de outras áreas do conhecimento, mas também pelos da psicologia narrativa, corrente psicoterapêutica minoritária da qual ele foi um dos fundadores, e um dos mais rigorosos, em termos conceptuais.

Através da reflexão feita concluímos que o conhecimento, nesse autor, se constitui em ação no mundo e não representação dele, o mundo é algo que emerge a partir de como nos movemos e agimos (conduta) em relaçáo dinâmica com o meio. A identidade pessoal pode descrever-se como processo de conhecimento contínuo do organismo vivo, capaz de vivenciar e ao mesmo tempo perceber e avaliar a sua própria experiência (autoconsciência). O ser humano opera/age na intersubjetividade, num mundo pluralista, com os seus congêneres, partilhando experiências e interpretando açóes (Guidano, 1987; Abreu \& Roso, 2003; Balbi, 2004).

Na relação terapêutica, o cliente conta a sua história e reconstrói as experiências/acontecimentos vividos, carregados de sentimentos. O terapeuta torna-se coconstrutor da mesma história na qual o cliente, mediante conexóes entre passado e presente, toma consciência do seu padrão organizacional (pessoal) (Gonçalves, 1995). As caraterísticas relacionais e emocionais de cada pessoa dependem desse padrão ontogenético que confere significado pessoal.

O "eu" chega a ver-se como um "mim" (quer dizer, como as outras pessoas do mundo circundante) só através da consciência que os cuidadores têm do seu comportamento. [...] Elaborar uma autoimagem consciente consiste em delimitar o perfil do "mim", partir do "eu" percebido. A diferenciaçáo si-mesmo/outro é um processo complexo, de múltiplos níveis, naquele que se sente como ator ("mim"), da sua singularidade e unicidade ("eu") que se encontra tanto em sintonia com os outros como na diferenciação no que respeita aos outros, sendo ambas as condiçôes igualmente necessárias para a experiência (Guidano, 1994a, p. 35).

A reter, sobretudo: no processo psicoterapêutico, torna-se de primordial importância entender a organização de significado pessoal (OSP) do cliente, pois esta traduz a forma como ele organiza e dá sentido à sua experiência (Guidano, 1987; 1991; Neimeyer, 1996; Goleman, 2000; Damásio, 2001; Abreu \& Roso, 2003; Nardi \& Moltedo, 2009; Nardi, Rezzonico, \& Bellantuono, 2010). 


\section{Referências}

Abreu, C., \& Roso, M. (2003). Psicoterapias Cognitivas e Construtivista: novas fronteiras da prática clínica. Porto Alegre: Artmed.

Ashby, R. (1962). Principles of the self-organizing system. In H. Von Foerster \& G. W. Zopf Jr. (Eds.), Principles of self-organization: Transactions of the University of Illinois Symposium (pp. 255-278). London, UK: Pergamon Press.

Balbi, J. (1994). Terapia Cognitiva Posracionalista. Conversaciones com Vittorio Guidano. Barcelona: Biblos.

Balbi, J. (1996). El método autobservacional: el rol del terapeuta como perturbador emocional. La técnica de la moviola. Buenos Aires: Centro de Terapia Cognitiva Posracionalista - CETEPO.

Balbi, J. (1997). El proceso terapéutico en la Terapia Cognitiva Posracionalista. In I. Caro (Ed.), Manual de terapias da cognitivas: estudio cuestión y procesos terapéuticos (pp. 381-398). Barcelona: Paidós.

Balbi, J. (2004) La mente narrativa: hacia una concepción posracionalista de la identidad personal. Buenos Aires: Paidós.

Balbi, J. (2007). Fundamentos teóricos y clinicos de la terapia cognitiva: orientación posracionalista. Buenos Aires: Centro de Terapia Cognitiva Posracionalista - CETEPO.

Boettcher, D., \& Pellanda, N. (2012). Sofrimento na perspectiva da complexidade: integrando todas as dimensōes do viver. In C. C. Oliveira, N. Pellanda, D. Boettcher, \& A. Reis (Ed.), Aprendizagem e sofrimento: narrativas (pp. 11-22). Santa Cruz do Sul: EDUNISC.

Carrijo, R. S., \& Rasera, E. F. (2010). Mudança em psicoterapia de grupo: reflexóes a partir da terapia narrativa. Psicologia Clínica, 22(1), 125-140.

Castrillón, J. V. (2011). Una aproximación a la terapia postracionalista desde Vittorio Guidano. Poiésis, 21, 1-4.

Damásio, A. (2001). O erro de Descartes. Mem Martins: Publicações Europa-América.

Dupuy, J. P. (1982). Ordres et désordres, enquête sur un nouveau paradigme. Paris: Seuil.

Gabalda, I. C. (1999). Manual de Psicoterapias Cognitivas: estado de la cuestión y procesos terapéuticos. Barcelona: Paidós.

Gardner, H. (2002). A nova ciência da mente: uma história da revoluçâo cognitiva. Lisboa: Relógio d'Água.

Gergen, K. J., \& Kaye, J. (1992). Therapy as social construction. London: SAGE.

Goleman, D. (2000). Inteligência Emocional. A teoria que redefine o que é ser inteligente. Rio de Janeiro: Objetiva.

Gonçalves, M. M. (1995). Auto-conhecimento e acesso ntrospectivo. Braga: Ed. I.E.P. da Universidade do Minho. 
Gonçalves, O. (1994). Cognitive narrative psychotherapy: The hermeneutic construction of alternative meaning. Journal of Cognitive Psychotherapy: An International Quaterly, 2(3), 5-25.

Gonçalves, O. (2002). Psicoterapia cognitiva narrativa. Bilbao: Editorial Descleé de Brouwer.

Guidano, V. (1987). The complexity of self: a developmental approach to psychopathology and therapy. Londres: The Guilford Press.

Guidano, V. (1990). El modelo posracionalista en psicología. Santiago del Chile: Universidad Academia de Humanismo Cristiano - Sociedad Chilena de Terapia Posracionalista.

Guidano, V. (1991). The self in process: toward a post-racionalist cognitive therapy. New York: Guilford Press.

Guidano, V. (1992). El processo psicoterapêutico. Santiago de Chile: Universidad Academia de Humanismo Cristiano - Sociedad Chilena de Terapia Posracionalista.

Guidano, V. (1994a). El si mismo en proceso. Hacia una terapia cognitiva post-racionalista. Barcelona: Paidos.

Guidano, V. (1994b). Aspectos del marco narrativo en la construcción de la experiencia humana. Santiago de Chile: Universidad Academia de Humanismo Cristiano Sociedad Chilena de Terapia Posracionalista.

Guidano, V. (1996). Las organizaciones de significado personal y su relación con la trama narrativa. Santiago del Chile: Universidad Academia de Humanismo Cristiano - Sociedad Chilena de Terapia Posracionalista.

Guidano, V., \& Liotti, G. (1983). Cognitive processes and emotional disorders. Londres: The Guilford Press.

Kuhn, T. (1962). The structure of scientific revolutions. Chicago: The University of Chicago Press.

Lodge, D. (2002). Thinks. London: Penguin books.

Mahoney, M. J. (1991). Human change processes: the scientific foundations of psychotherapy. New York: Basic Books.

Maturana, H. R., \& Varela, F. (1972). De máquinas e seres vivos: autopoiese - a organização do vivo. Porto Alegre: Artmed Editora.

Maturana, H., \& Poersken, B. (2004). From being to doing - The origins of the biology of cognition. Heidelberg: Carl-Auer.

Morales, M. O. (2008). The epistemological crisis in the theory of Vittorio Guidano. World Academy of Science, Engineering and Technology, 16, 501-504.

Nardi, B., \& Moltedo, A. (2009). Desarrollo del modelo de las organizaciones de significado personal de Vittorio Guidano: los procesos de construcción del sí en el modelo cognitivo post-racionalista evolutivo. Psicoperspectivas, 8(1), 93-111.

Nardi, B., Rezzonico, G., \& Bellantuono, C. (2010). Toward a scientific framework for the Personal Meaning Organization (PMO) paradigm: neuroimaging and genetic studies. Quaderni Italiani di Psichiatria, 29(3), 81-88.

Psic. Clin., Rio de Janeiro, vol. 27, N.I, P. 245-265, 2015 
Neimeyer, G. J. (1996). Evaluación constructivista. Barcelona: Paidós.

Ojeda, C. (2001). Francisco Varela y las ciências cognitivas. Revista Chilena de Neuropsiquiatria, 39, 286-295.

Pena, L., \& Oliveira, C. C. (2012). Auto-organização e psicoterapia. Saúde e Sociedade, 21(3), 668-674.

Quińones, A. (2001). El modelo cognitivo postracionalista: Hacia una reconceptualización teórica y crítica. Bilbao: Desclée de Brouwer.

Rorty, R. (1992). The linguistic turn essays in philosophical method. Chicago: The University of Chicago Press.

Ruiz, A. (2002) Fundamentos teóricos del enfoque post-racionalista. Santiago de Chile: Instituto de Terapia Cognitiva.

Salgado, J. (2004). Psicologia Narrativa e identidade: um estudo sobre auto-engano e organização pessoal. Maia: ISMAI - Instituto Superior da Maia.

Varela, F. (2001). Conhecer: as ciências cognitivas - tendências e perspectivas. Lisboa: Instituto Piaget.

Varela, F. Rosch, E., \& Thompson, E. (2001). A mente corpórea: ciência cognitiva e experiência humana. Lisboa: Instituto Piaget.

Varela, F., Thompson, E., \& Rosch, E. (1991). The embodied mind: cognitive science and human experience. Cambridge: The MIT Press.

Zagmutt, A. (2006). La evaluación de la Terapia Cognitiva Posracionalista. Conferência Plenária apresentada no VI Congresso Latino americano de Terapias Cognitivas, Buenos Aires, Argentina.

\section{Nota}

${ }^{1}$ Usamos esse neologismo para significar que procede do observador, é uma construção mental sua; o observador humano possui a capacidade de lidar com as suas representaçóes mentais como se elas possuíssem identidade ontológica, de modo reificado.

Recebido em 20 de novembro de 2013 Aceito para publicação em 16 de novembro de 2014

DOI: $10.1590 / 0103-56652015000100014$ 



\section{RESENHA}

Deficiências ou diversidade humana? 
